\title{
Profiling of actionable gene alterations in ovarian cancer by targeted deep sequencing
}

\author{
MASATAKA TAKENAKA ${ }^{1,4}$, MOTONOBU SAITO ${ }^{1}$, REIKA IWAKAWA ${ }^{1}$, NOZOMU YANAIHARA ${ }^{4}$, \\ MISATO SAITO ${ }^{4}$, MAMORU KATO $^{2}$, HITOSHI ICHIKAWA ${ }^{3}$, TATSUHIRO SHIBATA ${ }^{2}$, \\ JUN YOKOTA $^{1}$, AIKOU OKAMOTO ${ }^{4}$ and TAKASHI KOHNO ${ }^{1}$
}

\begin{abstract}
Divisions of ${ }^{1}$ Genome Biology, ${ }^{2}$ Cancer Genomics and ${ }^{3}$ Genetics, National Cancer Center Research Institute, Tokyo 104-0045; ${ }^{4}$ Department of Obstetrics and Gynecology, The Jikei University School of Medicine, Tokyo 105-8471, Japan
\end{abstract}

Received December 16, 2014; Accepted February 5, 2015

DOI: $10.3892 /$ ijo.2015.2951

\begin{abstract}
To construct a profile of therapeutically actionable gene alterations in the major histological types of ovarian cancer, 72 Japanese patients with surgically resected ovarian cancers were selected from an original cohort consisting of 267 patients who had not received pre-treatment before surgery. Somatic mutations and copy number alterations at 740 hotspots in 46 cancer-related genes were detected by deep sequencing of genomic DNAs obtained from snap-frozen tumor tissues using a next generation sequencer. The alterations were verified by Sanger sequencing and quantitative genomic PCR. Mutations and/or copy number aberrations which will make tumors respond to molecular targeting drugs were detected in nine genes of 35/72 (48.6\%) patients; PIK3CA (25.0\%), KRAS (13.9\%), ERBB2 (4.3\%), PTEN (2.8\%), RB1 (2.8\%), CDKN2A (2.8\%), AKT1 (1.4\%), CTNNB1 (1.4\%) and NRAS (1.4\%). These mutations tended to occur in a mutually exclusive manner. Non-serous histological type tumors showed such actionable gene alterations frequently $(32 / 47 ; 68.1 \%)$. Therefore, ovarian cancers, particularly of non-serous types, frequently carry gene aberrations that link to therapy using molecular targeting drugs.
\end{abstract}

\section{Introduction}

Ovarian cancer is a leading cause of cancer mortality from gynecological malignancies worldwide and, in the United States and Japan, accounts for $\sim 14,000$ and 4,600 deaths annually $(1,2)$. Ovarian cancer predominantly consists of four major histological types: serous, clear cell, endometrioid and mucinous adenocarcinomas. The incidence of each of these subtypes varies geographically: serous carcinoma is the

Correspondence to: Dr Takashi Kohno, Division of Genome Biology, National Cancer Center Research Institute, Tsukiji 5-1-1, Chuo-ku, Tokyo 104-0045, Japan

E-mail: tkkohno@ncc.go.jp

Key words: ovarian cancer, molecular targeted therapy, gene mutation, gene amplification, targeted deep sequencing most common type in Western and Asian countries; clear cell adenocarcinoma is prevalent (the second-most common) in Japan, but not in most of the other Asian countries, and is not prevalent in European countries (2,3). More than $70 \%$ of ovarian cancers are diagnosed as advanced stage cancers (3). The majority of these patients with advanced ovarian cancer show an initial response to platinum-based chemotherapy; however, most of these patients relapse (3). Consequently, the 5-year overall survival rate for ovarian cancer patients remains $<50 \%$ (3). Personalized therapy using molecular targeting drugs based on gene aberrations in tumor cells is a promising option to improve the therapeutic efficacy of the treatment for advanced ovarian cancer (4).

Recent genome-wide analysis has revealed alterations of ovarian cancer genomes (5-8). The most frequent alterations found are inactivating mutations in tumor suppressor genes, such as TP53, PTEN, BRCA1, BRCA2, and RB1, and in a SWI/SNF chromatin remodeling gene, $A R I D I A$. Other studies have detected activating mutations in the oncogenes $K R A S, B R A F, P I K 3 C A$ and $E R B B 2$, indicating that a subset of patients with ovarian cancer could benefit from therapy using existing molecular targeting drugs (5-7,9-11). However, the prevalence and specificity of such oncogene aberrations by clinicopathological factors, such as histological subtype, and whether the aberrations are present in a mutually exclusive manner, have not been fully examined in a defined population. Thus, we constructed a profile of actionable aberrations of 46 cancer-related genes in a cohort of 72 Japanese ovarian cancer patients. The cohort was chosen from 267 consecutive patients who had received surgery for ovarian cancer. Of these patients, 72 patients with ovarian cancer were surgically treated without prior chemotherapy, and the carcinomas in this cohort included all four histological tumor types and tumors at various stages.

\section{Materials and methods}

Patient cohort. Seventy-two patients with ovarian cancer (study cohort subjects) were selected from 267 consecutive patients with ovarian cancer (original cohort) who received surgery for ovarian cancer in the Department of Obstetrics and Gynecology, Jikei University School of Medicine, Tokyo, 
Japan, between 2000 and 2009. The 72 subjects were surgically treated patients with ovarian cancer who had not had prior chemotherapy. The selection procedure ensured that all four major histological types and stages of tumor were included in proportions similar to those found in the original cohort and were also representative of the proportions found in all Japanese ovarian cancer patients (Fig. 1) (2,3). Written informed consent was obtained from all patients. This study was approved by the Institutional Review Board of the contributing institutions.

The tumors and the adjacent non-cancerous tissues were macro-dissected and flash-frozen after surgery. All tumor tissues were resected from solid components without necrotic tissue in each tumor. Several tumor tissues were randomly selected for making paraffin sections and their cellularity was confirmed as being $>80 \%$.

Clinical information for each patient, including age, stage, histology, grade, residual tumor, treatment information, and survival time from primary surgery, was collected retrospectively. Tumors were staged in accordance with the International Federation on Gynecology and Obstetrics (FIGO) system. For each patient, the size of the residual tumor was recorded at the end of surgery. Tumors resistant to platinum-containing adjuvant chemotherapy (i.e., platinum resistance) were defined as those in patients who exhibited progression-free survival for $<6$ months after the completion of chemotherapy.

Cell lines. Fourteen ovarian cancer cell lines were used in this study. JHOC-5, JHOC-7, JHOC-8, and JHOC-9 were obtained from Riken BioResource Center (Tsukuba, Japan). HAC-2 was provided by Dr M. Nishida (Tsukuba University, Tsukuba, Japan). RMG-I and RMG-II were provided by Dr D. Aoki (Keio University, Tokyo, Japan). A2780 (undifferentiated carcinoma) was provided by Dr E. Reed (NCI, Bethesda, MD, USA) and 2008 was provided by Dr S.B. Howell (UCSD, San Diego, CA, USA). SKOV3, MCAS, TYK-nu, Ov-1063, and SW626 were obtained from ATCC (Rockville, MD, USA).

Deep sequencing of 46 cancer-related genes. Genomic DNA was extracted using a QIAamp DNA mini kit according to the manufacturer's instructions (Qiagen,Limburg, The Netherlands). Purified genomic DNA obtained from tumor tissues and cell lines (10 ng) was used for the library construction using the Ion AmpliSeq Cancer primer pool (cat. no. 4471262, Life Technologies, Rockville, MD, USA) that targets 739 mutational hotspot regions of 46 cancer-related genes and, additionally, a set of custom primers for the E17K mutation hotspot in the $A K T 1$ gene. Sequencing was run on the Ion Proton/PGM platform (Life Technologies). The median depth of coverage for aligned reads was $3,024 \times(2,010-35,534)$ by map quality $\geq 20$. Data analysis, including the hg19 human reference genome and variant calling, was carried out using the Torrent Suite Software v3.2 (Life Technologies).

Sanger sequencing. Genomic DNA (10 ng) was amplified by PCR using KAPA Taq DNA Polymerase (KAPA Biosystems, Woburn, MA, USA). PCR products were directly sequenced in both directions using the BigDye Termination kit and an ABI 3130xl DNA Sequencer (Applied Biosystems, Foster City, CA, USA).
Real-time genomic PCR. Copy number variations suggested by deep sequencing analysis were validated by real-time genomic PCR using a TaqMan Copy Number Assay and the ABI 7900HT real-time PCR system (Applied Biosystems). All TaqMan probes were purchased from Thermo Applied Biosystems: ERBB2 (ID Hs01932585_cn), PTEN (ID Hs05128032_cn), $R B 1$ (ID Hs00331762_cn and a set of custom primers), TP53 (ID Hs06424630_cn), and FGFRI (ID Hs02422066_cn) with RPPHI (cat. no. 4403328) as a reference. Data were analyzed using ABI PRISM 7900HT Sequence Detection Software v2.3 for copy number analysis.

Statistical analysis. Statistical analyses were performed using JMP software (SAS Institute, New York, NY, USA). Associations of the gene alterations with clinicopathological factors were evaluated using Fisher's exact test. For survival analysis, the Cox proportional hazard model was used for the univariate and multivariate analyses.

\section{Results}

Profiling of aberrations in 46 cancer-related genes in 72 ovarian cancers. Clinical and histological characteristics of the study subjects are provided in Table I. The frequency of clear cell adenocarcinoma in this cohort was higher than that found in other countries, reflecting known prevalence of ovarian cancer in Japan $(2,3)$.

We sequenced genomic DNAs from 72 ovarian cancer tissues, with a mean sequencing depth $>2,000$ in all cases, followed by Sanger sequencing validation (representative results in Fig. 2A). The results revealed 115 single-nucleotide variations (SNVs), but no insertions/deletions, at 740 hotspot sites in 46 cancer-related genes. The 115 SNVs were of 50 distinct types, and included 64 SNVs (43 types) that were deduced as somatic according to data from the Catalogue of Somatic Mutation in Cancer (COSMIC) database (http:// cancer.sanger.ac.uk/cancergenome/projects/cosmic/). The somatic nature of these mutations was verified in some samples by Sanger sequencing of DNAs from corresponding non-cancerous tissues (Table II). In addition, another SNV detected in a single case, $P I K 3 C A-\mathrm{N} 345 \mathrm{H}$, caused an amino acid change in the PIK3CA protein, which is recurrently mutated in human cancers. Therefore, these 65 SNVs (44 types) were considered to represent somatic mutations. Furthermore, Sanger sequencing of DNAs from non-cancerous tissue revealed that the remaining $50 \mathrm{SNVs}$ (six types) consisted of two missense mutations and 48 single-nucleotide polymorphisms (four types). Thus, in total, 67 somatic missense mutations (46 types) were detected in the study cohort (Table II).

TP53 (38.9\%), PIK3CA (25.0\%), and KRAS (13.9\%) were the three most frequently mutated genes (Table III). The other genes in which mutations were found were PTEN, FGFR2, $C D K N 2 A, A K T 1, C T N N B 1, N R A S, M E T$ and KIT. The frequency of the TP53, PIK3CA and KRAS mutations were different in each histological subtype. TP53 was more frequently mutated in serous carcinomas $(56.0 \%)$ than in the other subtypes $(\mathrm{P}=0.042$ by Fisher's exact test, compared with non-serous patients with ovarian cancer; $29.8 \%$ ); PIK3CA was more frequently mutated in clear cell carcinomas $(48.1 \%)$ than in the other subtypes 

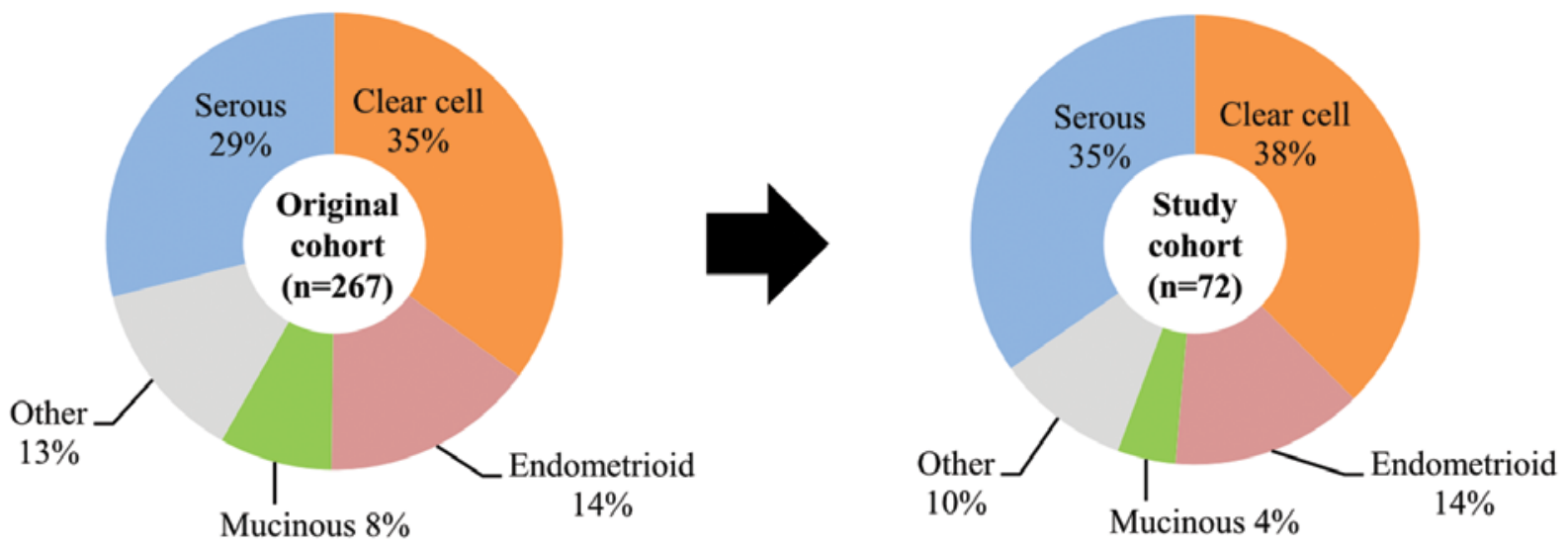

Figure 1. Preparation of the study cohort. The study cohort included all four representative histological types of ovarian carcinoma in proportions similar to those of the original cohort.

Table I. Characteristics of 72 Japanese patients with ovarian cancer.

\begin{tabular}{|c|c|c|}
\hline $\begin{array}{l}\text { Clinicopathological } \\
\text { variables }\end{array}$ & $\begin{array}{l}\text { No. of patients } \\
\text { with ovarian cancer }\end{array}$ & $\begin{array}{c}\text { Frequency } \\
(\%)\end{array}$ \\
\hline \multicolumn{3}{|l|}{ Age } \\
\hline$<60$ & 49 & 68 \\
\hline$\geq 60$ & 23 & 32 \\
\hline \multicolumn{3}{|l|}{ Stage } \\
\hline I & 31 & 43 \\
\hline II & 7 & 10 \\
\hline III & 27 & 37 \\
\hline IV & 7 & 10 \\
\hline \multicolumn{3}{|l|}{ Histology } \\
\hline Clear cell & 27 & 37 \\
\hline Endometrioid & 10 & 14 \\
\hline Mucinous & 3 & 4 \\
\hline Other & 7 & 10 \\
\hline Serous & 25 & 35 \\
\hline \multicolumn{3}{|l|}{ Grade } \\
\hline $\mathrm{G} 1$ & 11 & 15 \\
\hline $\mathrm{G} 2$ & 15 & 21 \\
\hline G3 & 11 & 15 \\
\hline Unknown/not graded & 35 & 49 \\
\hline \multicolumn{3}{|l|}{ Residual tumor (cm) } \\
\hline$\leq 1$ & 55 & 76 \\
\hline$>1$ & 17 & 24 \\
\hline \multicolumn{3}{|l|}{ Adjuvant chemotherapy } \\
\hline Platinum & 1 & 1 \\
\hline Platinum + Taxane & 45 & 63 \\
\hline Platinum + Irinotecan & 18 & 25 \\
\hline None & 8 & 11 \\
\hline \multicolumn{3}{|l|}{ Platinum resistance } \\
\hline Sensitive & 52 & 72 \\
\hline Resistant & 11 & 15 \\
\hline Not evaluated & 9 & 13 \\
\hline
\end{tabular}

( $\mathrm{P}<0.001$ by Fisher's exact test, compared with non-clear cell carcinoma patients; $11.1 \%)$, as previously indicated (7,10,12-14). KRAS was more frequently mutated in clear cell carcinomas (25.9\%) than in the other subtypes, consistent with previous reports $(\mathrm{P}=0.034$ by Fisher's exact test, compared with nonclear cell carcinoma patients; 6.7\%) (9,10,15-17).

Copy number aberrations (CNAs) in the 46 genes were deduced by calculating the ratios of the sequence read fraction in each tumor compared to the sequence read fraction of a single non-cancerous tissue subjected to sequencing. Loci that were potentially affected were selected using the criteria of $>2$-times gains and $<1 / 4$-times losses (suggesting homozygous deletion), followed by verification with quantitative genomic PCR analysis (Fig. 2B). Ten CNAs in PTEN (1 case), RBI (4 cases), TP53 (1 case), ERBB2 (3 cases) and FGFRI (1 case) were suggested in 10 tumors, and six of them were confirmed by quantitative genomic PCR analysis; gains of the ERBB2 gene in three patients (4.2\%); and homozygous deletions of the $R B 1$ gene in two patients $(2.8 \%)$ and of the PTEN gene in a patient (1.4\%) (Table III).

Profile of cancer-related gene actionable alterations in the histological subtypes. A profile of therapeutically actionable alterations was next constructed (Fig. 2C). Genetic alterations, possibly affecting the gene function and sensitivity to existing therapeutic drugs or strategies, were selected here as actionable alterations. ERBB2 amplification is a well-known actionable alteration (18-20). All the SNVs detected in the $A K T 1, C T N N B 1, K R A S, P I K 3 C A$ and NRAS genes (31 SNVs in total) affected hotspot amino acids, and were considered actionable as targets for existing protein kinase inhibitors (21-25). In addition, the SNVs found in the CDKN2A and $P T E N$ genes, and the RB and PTEN homozygous deletions, were considered actionable as they are linked to responsiveness to several inhibitors (26-28).

In total, 41 actionable gene alterations were detected in 35 of $72(48.6 \%)$ patients (Fig. 3A). These mutations tended to exist in a mutually exclusive manner (Fig. 2C). In 30 of the $35(85.7 \%)$ patients there was only one actionable alteration, while five patients had multiple alterations: one patient had mutations in three genes and four patients had mutations in two genes. In these five patients, fractions of mutant alleles 
Table II. Somatic SNVs detected in 72 patients with ovarian cancer.

\begin{tabular}{|c|c|c|c|c|c|c|c|c|}
\hline Gene & $\begin{array}{l}\text { Position } \\
\text { (ch: bp) }\end{array}$ & $\begin{array}{c}\text { Nucleotide } \\
\text { change }\end{array}$ & $\begin{array}{c}\text { AA } \\
\text { change }\end{array}$ & COSMIC ID & $\begin{array}{l}\text { Variant } \\
\text { rate }(\%)\end{array}$ & SNV type & $\begin{array}{l}\text { Validated } \\
\text { as somatic } \\
\text { change }\end{array}$ & $\begin{array}{l}\text { Mutated } \\
\text { sample }\end{array}$ \\
\hline \multirow[t]{24}{*}{ TP53 } & 17: 7,579,882 & G31C & E11Q & COSM11606 & 52.9 & Non-synonymous & $\mathrm{C}$ & $\mathrm{T} 12$ \\
\hline & 17: 7,579,358 & G329C & $\mathrm{R} 110 \mathrm{P}$ & COSM11250 & 48.6 & Non-synonymous & $\mathrm{C}$ & T55 \\
\hline & 17: 7,578,535 & A395G & K132R & COSM11582 & 32.9 & Non-synonymous & $\mathrm{C}$ & $\mathrm{T} 3$ \\
\hline & 17: 7,578,534 & G396C & $\mathrm{K} 132 \mathrm{~N}$ & COSM43963 & 83.9 & Non-synonymous & $\mathrm{C}, \mathrm{S}$ & $\mathrm{T} 44$ \\
\hline & 17: 7,578,526 & G404A & $\mathrm{C} 135 \mathrm{Y}$ & COSM10801 & 70.5 & Non-synonymous & $\mathrm{C}$ & $\mathrm{T} 8$ \\
\hline & $17: 7,578,461$ & G469T & V157F & COSM10670 & 64.4 & Non-synonymous & $\mathrm{C}, \mathrm{S}$ & $\mathrm{T} 22$ \\
\hline & $17: 7,578,454$ & $\mathrm{C} 476 \mathrm{~T}$ & A159V & COSM11148 & 59.0 & Non-synonymous & $\mathrm{C}, \mathrm{S}$ & $\mathrm{T} 33$ \\
\hline & $17: 7,578,406$ & G524A & $\mathrm{R} 175 \mathrm{H}$ & COSM10648 & $32.1-76.4$ & Non-synonymous & $\mathrm{C}, \mathrm{S}$ & $\mathrm{T} 23, \mathrm{~T} 50$, \\
\hline & & & & $\mathrm{COS}$ & & & & $\begin{array}{l}\text { Т57, Т59 } \\
\text { T16, T39 }\end{array}$ \\
\hline & $\begin{array}{l}1 / .7,5 / 8,2 / 1 \\
17.7578260\end{array}$ & & П195L & & 673 & & & $\begin{array}{c}110,139 \\
\mathrm{~T} 65\end{array}$ \\
\hline & 17:7,5/8,269 & c5801 & L194F & COSMI0995 & $6 \% .3$ & Non-synonymous & $\mathrm{C}$ & 165 \\
\hline & $17: 7,578,263$ & C586T & R196X & COSM10705 & 65.6 & Stop-gain & $\mathrm{C}, \mathrm{S}$ & $\mathrm{T} 48$ \\
\hline & $17: 7,578,257$ & G592T & E198X & COSM44241 & 50.8 & Stop-gain & $\mathrm{C}, \mathrm{S}$ & T30 \\
\hline & $17: 7,578,212$ & C637T & $\mathrm{R} 213 \mathrm{X}$ & COSM10654 & 52.3 & Stop-gain & $\mathrm{C}, \mathrm{S}$ & $\mathrm{T} 21$ \\
\hline & 17: 7,578,203 & G646A & V216M & COSM10667 & 71.8 & Non-synonymous & $\mathrm{C}$ & $\mathrm{T} 13$ \\
\hline & $17: 7,578,203$ & G646T & V216L & COSM11210 & 81.3 & Non-synonymous & $\mathrm{C}, \mathrm{S}$ & T67 \\
\hline & 17: 7,578,196 & T653G & V218G & COSM44198 & 71.5 & Non-synonymous & $\mathrm{C}$ & $\mathrm{T} 43$ \\
\hline & $17: 7,577,538$ & G743A & R248Q & COSM10662 & 76.1 & Non-synonymous & $\mathrm{C}$ & T46 \\
\hline & $17: 7,577,120$ & G818A & $\mathrm{R} 273 \mathrm{H}$ & COSM10660 & $51.1-67.1$ & Non-synonymous & $\mathrm{C}$ & $\mathrm{T} 49, \mathrm{~T} 51$ \\
\hline & $17: 7,577,114$ & G824T & $\mathrm{C} 275 \mathrm{~F}$ & COSM10701 & 59.5 & Non-synonymous & $\mathrm{C}, \mathrm{S}$ & T69 \\
\hline & 17: 7,577,106 & C832A & $\mathrm{P} 278 \mathrm{~T}$ & COSM43697 & 22.1 & Non-synonymous & $\mathrm{C}$ & T36 \\
\hline & 17: 7,577,094 & $\mathrm{C} 844 \mathrm{~T}$ & R282W & COSM10704 & 94.3 & Non-synonymous & $\mathrm{C}, \mathrm{S}$ & $\mathrm{T} 25$ \\
\hline & $17: 7,577,022$ & C916T & R306X & COSM10663 & 55.1 & Stop-gain & $\mathrm{C}$ & T58 \\
\hline & 17: 7,574,003 & $\mathrm{C} 1024 \mathrm{~T}$ & $\mathrm{R} 342 \mathrm{X}$ & COSM11073 & 83.1 & Stop-gain & $\mathrm{C}$ & T68 \\
\hline \multirow[t]{9}{*}{$\mathrm{PIK} \mathrm{CA}^{\mathrm{a}}$} & $3: 178,916,876$ & G263A & R88Q & COSM746 & 32.5 & Non-synonymous & $\mathrm{C}$ & $\mathrm{T} 14$ \\
\hline & 3: $178,921,551$ & A1033C & $\mathrm{N} 345 \mathrm{H}$ & & 65.6 & Non-synonymous & & $\mathrm{T} 45$ \\
\hline & 3: $178,936,074$ & C1616G & P539R & COSM759 & 45.5 & Non-synonymous & $\mathrm{C}, \mathrm{S}$ & T71 \\
\hline & 3: $178,936,082$ & G1624A & E542K & COSM760 & $10.1-22.2$ & Non-synonymous & $\mathrm{C}, \mathrm{S}$ & $\begin{array}{l}\text { T6, T42, } \\
\text { T57, T63 }\end{array}$ \\
\hline & 3: $178,936,091$ & G1633A & E545K & COSM763 & $18.8-71.6$ & Non-synonymous & $\mathrm{C}$ & T53, Т60 \\
\hline & 3: $178,936,094$ & C1636A & Q546K & COSM766 & $92.8-93.4$ & Non-synonymous & $\mathrm{C}$ & $\mathrm{T} 27, \mathrm{~T} 28$ \\
\hline & 3: $178,952,085$ & A3140T & H1047L & COSM776 & 31.6 & Non-synonymous & $\mathrm{C}$ & T20 \\
\hline & 3: $178,952,085$ & A3140G & H1047R & COSM775 & $12.5-42.4$ & Non-synonymous & $\mathrm{C}, \mathrm{S}$ & $\mathrm{T} 4, \mathrm{~T} 7$ \\
\hline & & & & & & & & T35, T36 \\
\hline \multirow[t]{4}{*}{$\mathrm{KRAS}^{\mathrm{a}}$} & $12: 25,398,284$ & G35C & G12A & COSM522 & $6.8-22.1$ & Non-synonymous & $\mathrm{C}$ & T15, T63 \\
\hline & $12: 25,398,284$ & G35A & G12D & COSM521 & $29.1-95.7$ & Non-synonymous & $\mathrm{C}, \mathrm{S}$ & $\begin{array}{c}\text { T10, T54, } \\
\text { T72 }\end{array}$ \\
\hline & 12: $25,398,284$ & G35T & G12V & COSM520 & $6.4-58.3$ & Non-synonymous & $\mathrm{C}, \mathrm{S}$ & T5, T29, \\
\hline & 8,285 & $34 \mathrm{C}$ & $12 \mathrm{R}$ & M518 & & on-synonymous & $\mathrm{C}, \mathrm{S}$ & $\mathrm{T} 4$ \\
\hline \multirow[t]{2}{*}{$\mathrm{CDKN}_{2 \mathrm{~A}^{\mathrm{a}}}$} & $9: 21,971,161$ & A197G & H66R & COSM14253 & 36.5 & Non-synonymous & $\mathrm{C}$ & $\mathrm{T} 50$ \\
\hline & 9: $21,971,203$ & $\mathrm{~T} 155 \mathrm{G}$ & M52R & COSM608436 & 50.0 & Non-synonymous & $\mathrm{C}$ & T51 \\
\hline \multirow[t]{2}{*}{ FGFR2 } & $10: 123,279,677$ & $\mathrm{C} 755 \mathrm{G}$ & S252W & COSM36903 & 21.3 & Non-synonymous & $\mathrm{C}$ & $\mathrm{T} 36$ \\
\hline & $10: 123,258,036$ & $\mathrm{~A} 1645 \mathrm{C}$ & $\mathrm{N} 549 \mathrm{H}$ & COSM250083 & 38.7 & Non-synonymous & $\mathrm{C}, \mathrm{S}$ & $\mathrm{T} 14$ \\
\hline \multirow[t]{2}{*}{ PTEN $^{\mathrm{a}}$} & 10: 89,711,902 & T520G & Y174D & COSM28897 & 73.6 & Non-synonymous & $\mathrm{C}$ & $\mathrm{T} 20$ \\
\hline & 10: 89,720,799 & T950G & V317G & & 41.9 & Non-synonymous & $\mathrm{S}$ & $\mathrm{T} 44$ \\
\hline $\mathrm{AKT}^{\mathrm{a}}$ & $14: 105,246,551$ & G49A & $\mathrm{E} 17 \mathrm{~K}$ & COSM33765 & 23.0 & Non-synonymous & $\mathrm{C}$ & $\mathrm{T} 11$ \\
\hline $\mathrm{CTNNB}^{\mathrm{a}}$ & $3: 41,266,103$ & G100C & G34R & COSM5684 & 16.8 & Non-synonymous & $\mathrm{C}$ & $\mathrm{T} 31$ \\
\hline KIT & 4: $55,593,464$ & A1621C & M541L & COSM28026 & 56.2 & Non-synonymous & $\mathrm{C}$ & $\mathrm{T} 2$ \\
\hline MET & 7: $116,411,966$ & T3005C & V1002A & & 52.2 & Non-synonymous & $\mathrm{S}$ & T65 \\
\hline $\mathrm{NRAS}^{\mathrm{a}}$ & 1: $115,258,747$ & G35A & G12D & COSM564 & 60.4 & Non-synonymous & $\mathrm{C}$ & $\mathrm{T} 20$ \\
\hline
\end{tabular}

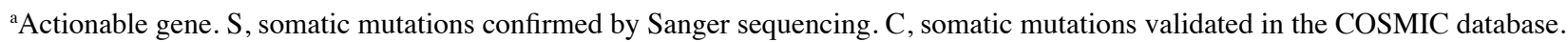


A
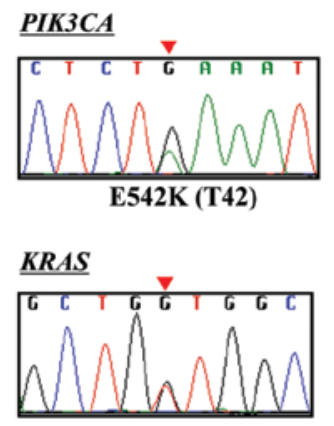

G12V (T37)

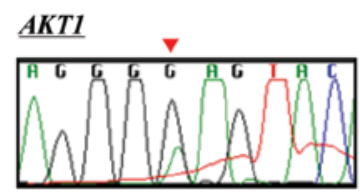

E17K (T11)

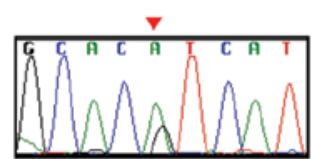

H1047R (T11)

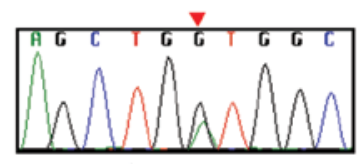

G12D (T72)

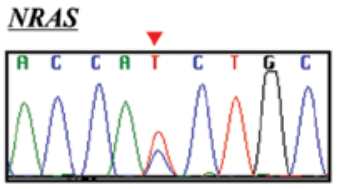

G12D (T20)
B
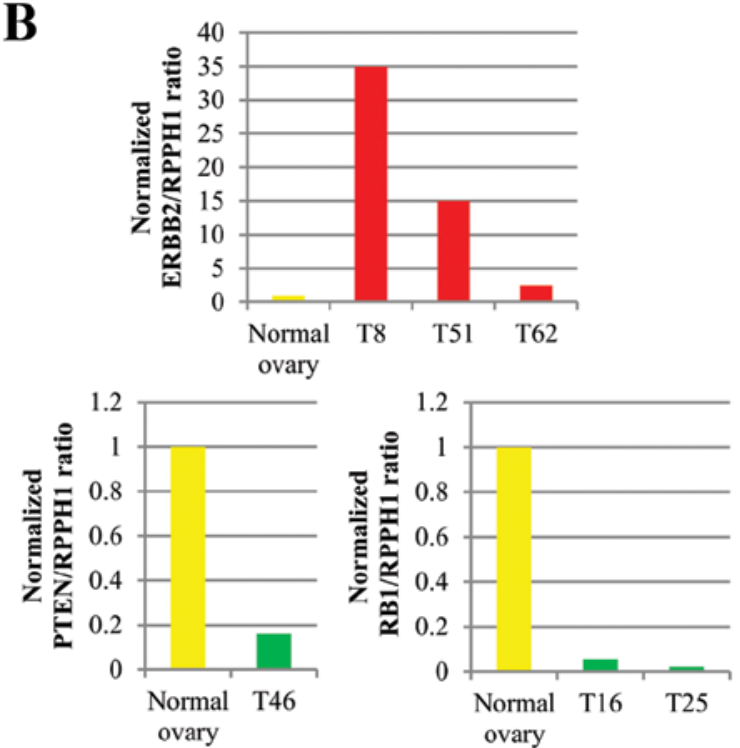

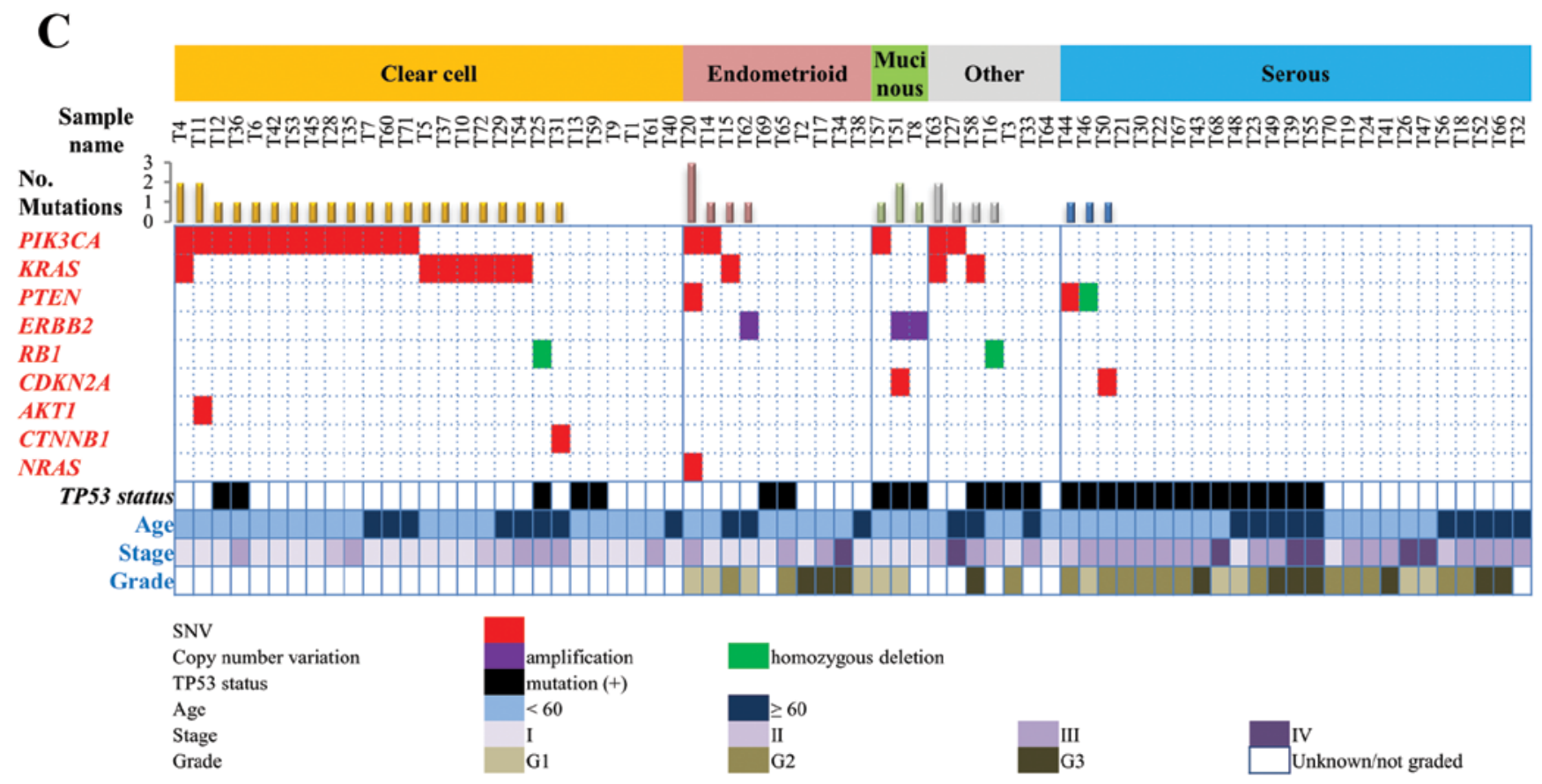

Figure 2. Validation of the somatic mutation and copy number validation, and profiling of actionable gene alterations. (A) Representative hotspot mutations validated by Sanger DNA sequencing. (B) Results of real-time genomic PCR analysis for ERBB2 amplification and the homozygous deletions of PTEN and RB1. (C) Actionable gene alterations in 72 Japanese ovarian carcinomas. Cases are arranged from left to right by histological type: clear cell, endometrioid, mucinous, other, and serous. The total number of actionable genetic alterations is indicated by vertical bars.

were not evidently different between mutated genes, therefore, these mutations were likely to have occurred in similar fractions of cancer cells in each tissue. Of the different histological subtypes, clear cell carcinomas showed the highest frequency of actionable alterations $(21 / 27 ; 77.8 \%)$, whereas serous carcinomas had the lowest frequency $(3 / 25 ; 12.0 \%$; Fig. $3 \mathrm{~B}$ and $\mathrm{C})$. This was largely due to the differential occurrence of PIK3CA mutations in the different histological subtypes (Fig. 2C). In non-serous carcinomas, the majority $(32 / 47 ; 68.1 \%)$ had at least one actionable mutation $(\mathrm{P}<0.0001$ by Fisher's exact test, compared with serous carcinomas).

We proceeded to investigate the associations between the actionable alterations and clinicopathological factors (Fig. 4).
However, we identified no significant associations between any of the actionable alterations and age, stage, differentiation grade, presence/absence of residual tumor, or therapeutic response to platinum therapy. Actionable gene alterations were not significantly associated with prognosis, either among all cases (data not shown) or among non-serous carcinomas in particular.

\section{Discussion}

We constructed an actionable gene alteration profile of ovarian cancer of a Japanese population using the deep genome sequencing method. The majority $(48.6 \%)$ of ovarian cancers, in particular non-serous carcinomas $(68.1 \%)$, were found to 
Table III. SNVs and CNAs detected in 72 ovarian cancers.

\begin{tabular}{|c|c|c|c|c|c|c|c|}
\hline \multirow[b]{2}{*}{$\begin{array}{l}\text { Type of } \\
\text { alteration }\end{array}$} & \multicolumn{7}{|c|}{ No $(\%)$} \\
\hline & Gene/alteration & $\begin{array}{l}\text { Total } \\
(n=72)\end{array}$ & $\begin{array}{l}\text { Clear cell } \\
(n=27)\end{array}$ & $\begin{array}{l}\text { Serous } \\
(n=25)\end{array}$ & $\begin{array}{l}\text { Endometrioid } \\
\qquad(\mathrm{n}=10)\end{array}$ & $\begin{array}{l}\text { Mucinous } \\
\qquad(n=3)\end{array}$ & $\begin{array}{c}\text { Others } \\
(n=7)\end{array}$ \\
\hline \multirow[t]{12}{*}{ SNV } & TP53 & $28(38.9)$ & $5(18.5)$ & $14(56.0)$ & $2(7.1)$ & $3(100)$ & $4(14.3)$ \\
\hline & $P I K 3 C A^{\mathrm{a}}$ & $18(25.0)$ & $13(48.1)$ & 0 & $2(20.0)$ & $1(33.3)$ & $2(28.6)$ \\
\hline & $K R A S^{\mathrm{a}}$ & $10(13.9)$ & 7 (25.9) & 0 & $1(10.0)$ & 0 & $2(28.6)$ \\
\hline & $P T E N^{\mathrm{a}}$ & $2(2.8)$ & 0 & $1 \quad(4.0)$ & $1(10.0)$ & 0 & 0 \\
\hline & $F G F R 2$ & $2(2.8)$ & $1 \quad(3.7)$ & 0 & $1(10.0)$ & 0 & 0 \\
\hline & $C D K N 2 A^{\mathrm{a}}$ & $2(2.8)$ & 0 & $1 \quad(4.0)$ & 0 & $1(33.3)$ & 0 \\
\hline & $A K T 1^{\mathrm{a}}$ & $1 \quad(1.4)$ & $1 \quad(3.7)$ & 0 & 0 & 0 & 0 \\
\hline & $C T N N B 1^{\mathrm{a}}$ & $1 \quad(1.4)$ & $1 \quad(3.7)$ & 0 & 0 & 0 & 0 \\
\hline & $N R A S^{\mathrm{a}}$ & $1 \quad(1.4)$ & 0 & 0 & $1(10.0)$ & 0 & 0 \\
\hline & $M E T$ & $1 \quad(1.4)$ & 0 & 0 & $1(10.0)$ & 0 & 0 \\
\hline & $K I T$ & $1 \quad(1.4)$ & 0 & 0 & $1(10.0)$ & 0 & 0 \\
\hline & Total & 67 & 28 & 16 & 10 & 5 & 8 \\
\hline \multirow[t]{4}{*}{ CNAs } & $E R B B 2^{\text {a }}$ gain & $3(4.3)$ & 0 & 0 & $1(10.0)$ & $2(67.7)$ & 0 \\
\hline & $R B^{\mathrm{a}} /$ homozygous deletion & $2(2.8)$ & $1 \quad(3.7)$ & 0 & 0 & 0 & $1(14.3)$ \\
\hline & $P T E N^{\mathrm{a}}$ /homozygous deletion & $1 \quad(1.4)$ & 0 & $1(4.0)$ & 0 & 0 & 0 \\
\hline & Total & 6 & 1 & 1 & 1 & 2 & 1 \\
\hline
\end{tabular}

${ }^{\mathrm{a} A c t i o n a b l e ~ g e n e . ~}$

A

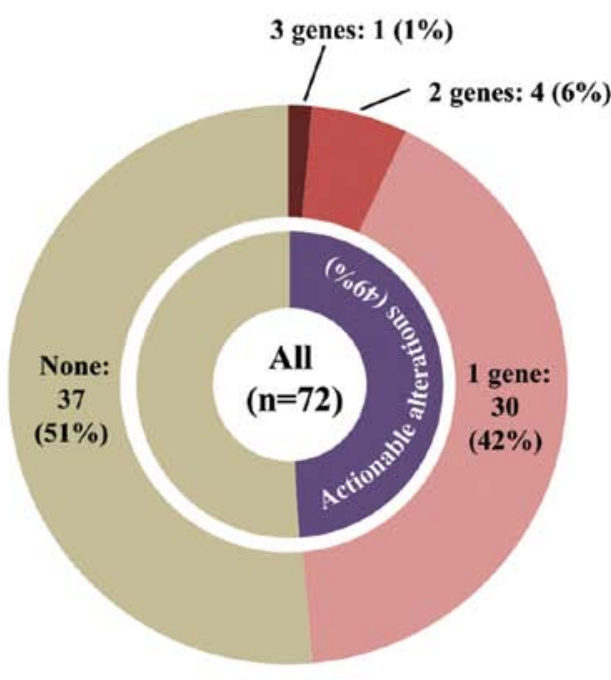

C

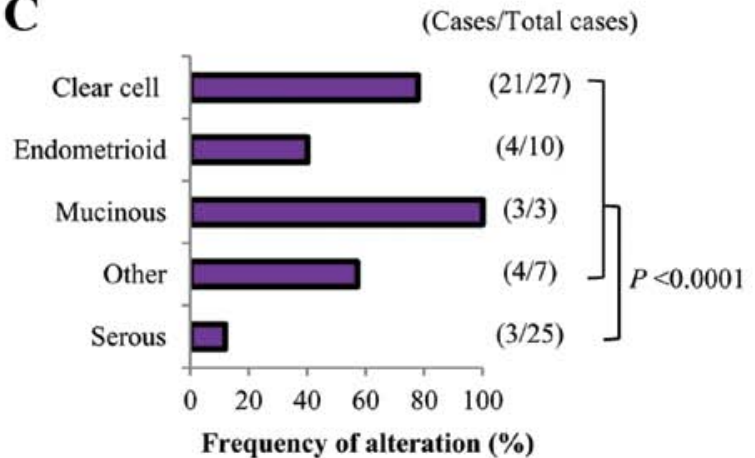

B
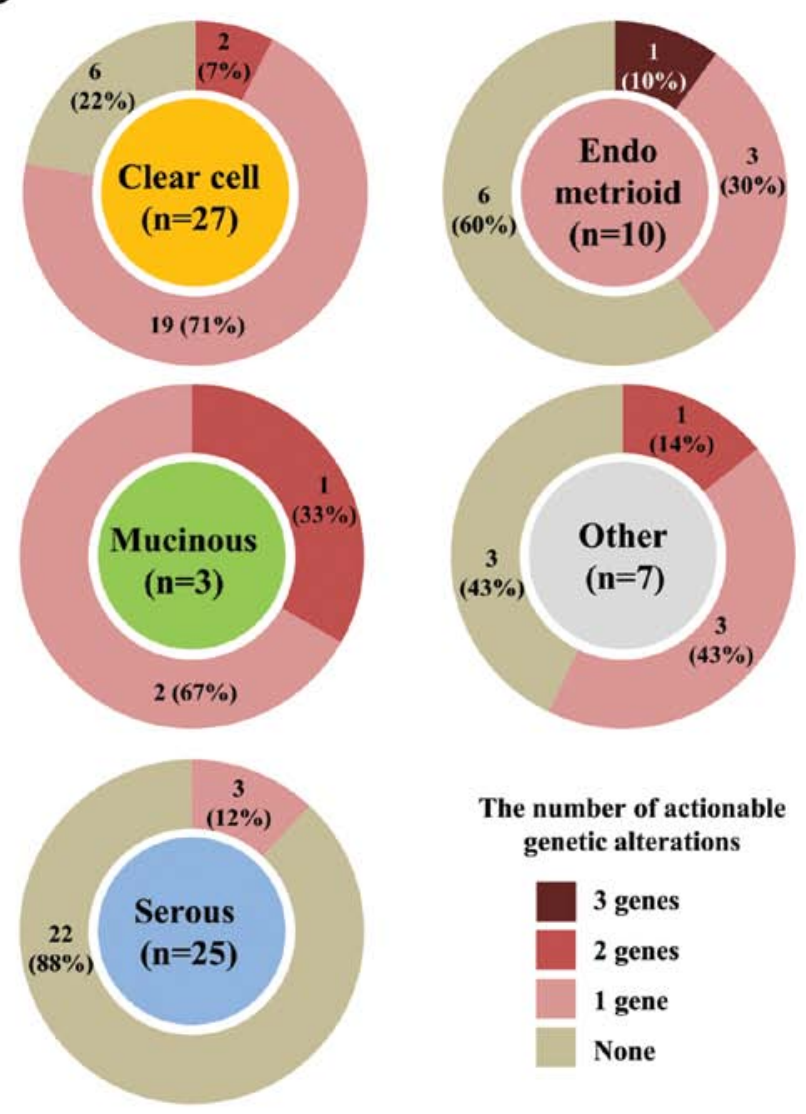

The number of actionable genetic alterations

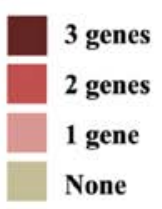

Figure 3. Distribution of actionable gene alterations in 72 ovarian carcinomas. (A) The number of genes with actionable alterations detected in 72 patients with ovarian cancer. The center circle represents the fraction of patients with ovarian cancer with at least one actionable event. (B) The number of actionable alterations for each histological subtype. (C) Frequencies of actionable gene alterations according to histological subtype. P-value by Fisher's exact test is shown. 

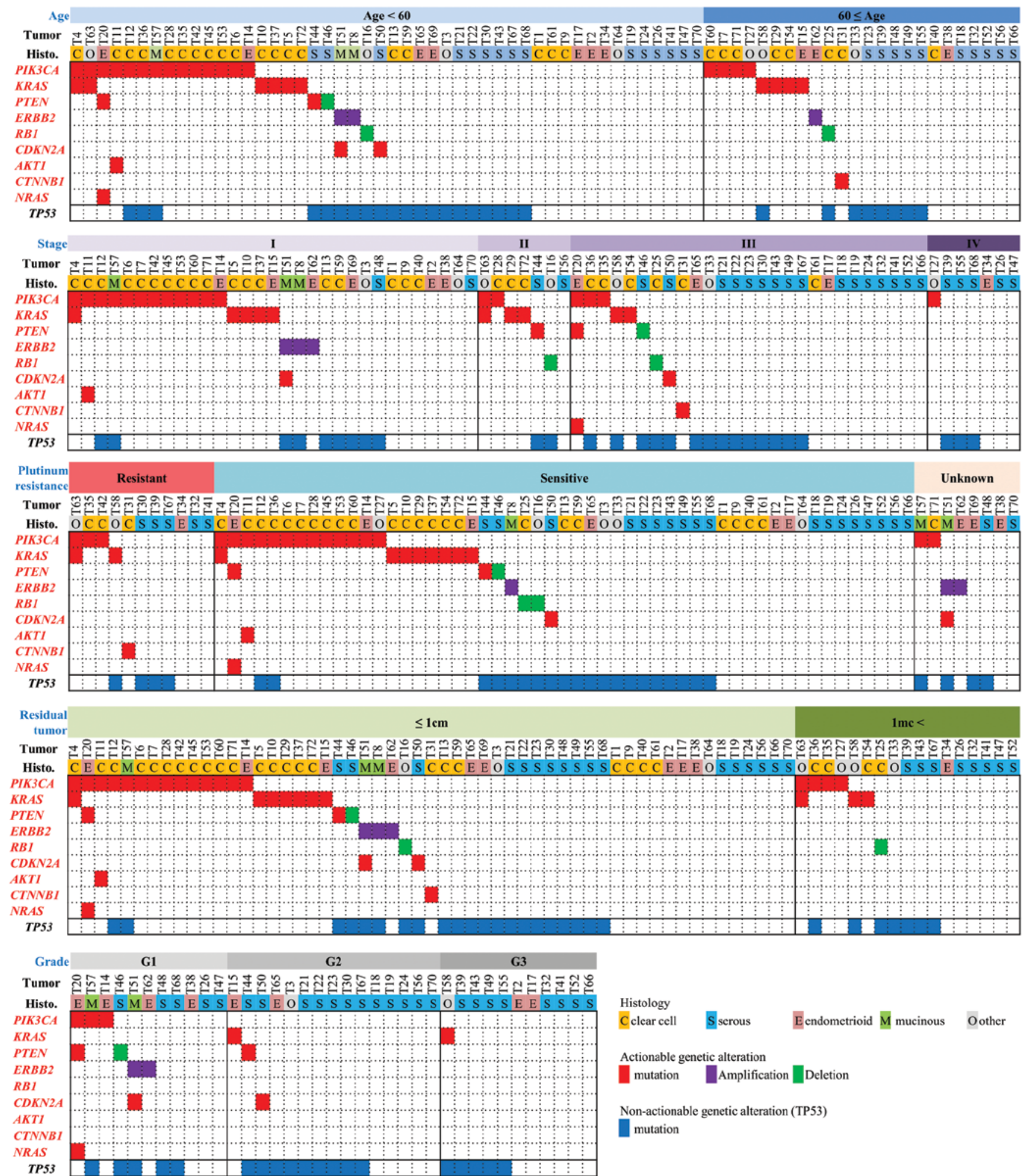

Figure 4. Distributions of actionable genetic alterations stratified by age, stage, platinum resistance, residual tumors and grade. Sample name, histological subtype and TP53 mutations are shown.

carry at least one actionable alteration in the 46 cancer-related genes examined. The TP53, PIK3CA and KRAS genes were top three mutation genes. Consistent with previous reports $(13,29), T P 53$ and $P I K 3 C A$ were preferentially mutated in serous and clear cell carcinoma, respectively, while KRAS was preferentially mutated in clear cell carcinoma (Table III). Distinct molecular features of Japanese ovarian cancers were suggested. Frequency of $K R A S$ mutation in clear cell carcinoma $(25.9 \%)$ was higher than that in cases described previously (7\%) (13), while frequency of hotspot TP53 mutations $(57.8 \%)$ in high-grade serous carcinoma were less than that in Caucasian cases $(>80 \%)(7,12)$. These results provide basic information for the understanding of ovarian carcinogenesis by different ethnicity. 


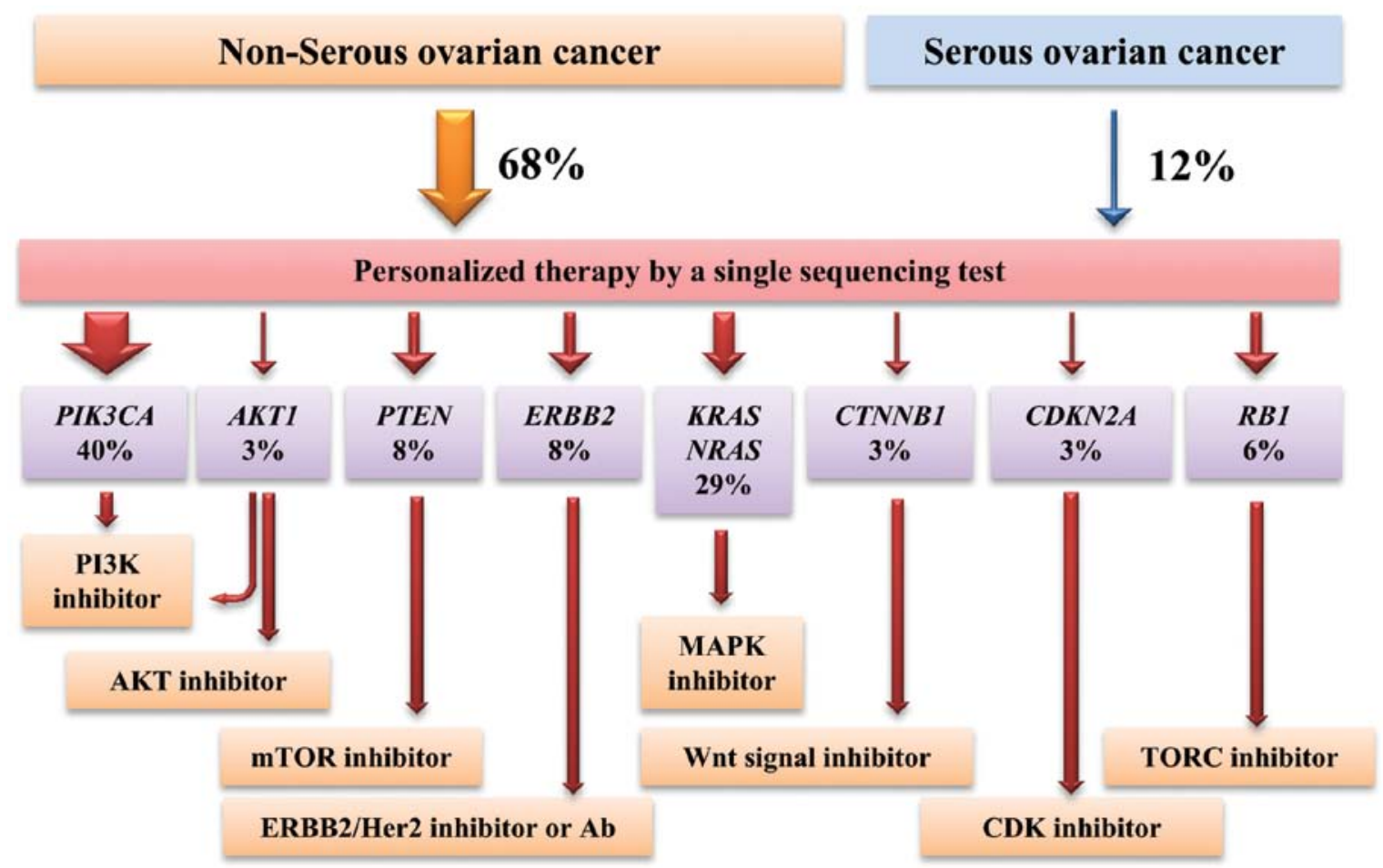

Figure 5. Potential personalized therapy for ovarian cancer based on actionable gene alterations. Percentages used in the upper tier, 68 and $12 \%$, are those of non-serous and serous tumors, respectively, with at least one actionable gene alteration. The percentages of the above cases with actionable alterations in the indicated genes are shown in the lower tier. Candidate inhibitory drugs for each actionable gene alteration are shown at the bottom.

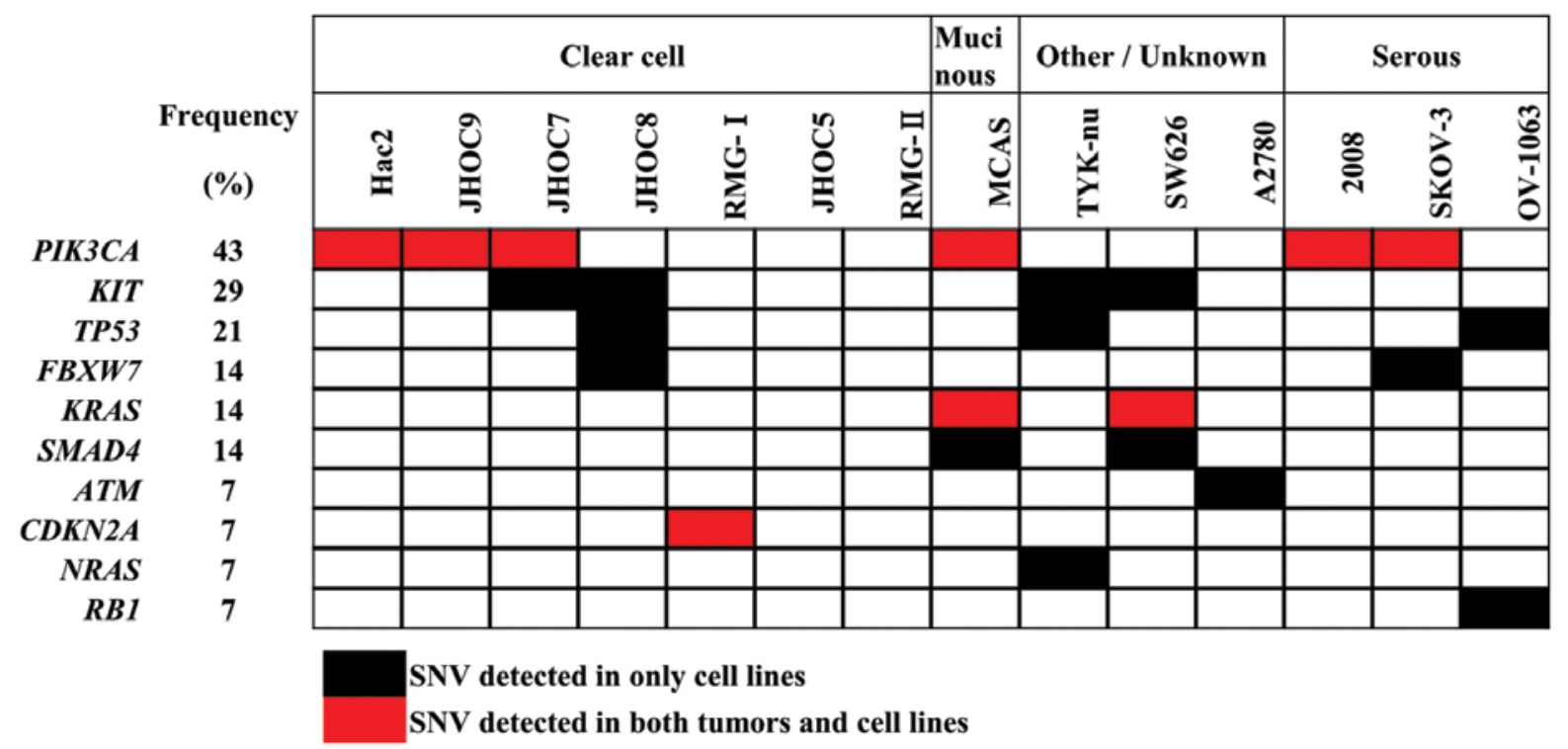

Figure 6. Mutational profile of 14 ovarian cancer cell lines. Mutations detected only in cell lines are marked in black and those detected in both surgical specimens and cell lines are marked in red.

According to this profile, therapeutic strategy using molecularly targeted drugs can be considered (Fig. 5). Tumors with PIK3CA, AKT1 and PTEN mutations, which cause activation of the PI3K-AKT-mTOR pathway, are targetable by $\mathrm{PI} 3 \mathrm{~K} / \mathrm{AKT} / \mathrm{mTOR}$ inhibitors $(21,24,27)$. Indeed, the results of clinical trials have demonstrated that ovarian tumors with PIK3CA mutations exhibit a high response rate to these inhibitors (30). Tumors with $E R B B 2$ amplification are targetable by ERBB2 inhibitors or antibodies, as evidenced by observations that ovarian cancer cases with $E R B B 2$ amplification exhibit high response rates to an anti-ERBB2 antibody drug $(20,31,32)$.

Tumors with KRAS and NRAS mutations can be targeted by MAPK inhibitors, although in many cancers therapeutic responses are less than expected based on clinical trials (33). Sorafenib, which targets RAF and other kinases and inhibits the RAS-RAF-ERK pathway, has been shown to be an effective treatment for two Japanese patients with recurrent ovarian clear cell carcinoma (34). Selumetinib, a MEK1/MEK2 inhib- 
Table IV. SNVs detected in 14 ovarian cancer cell lines.

\begin{tabular}{|c|c|c|c|c|c|c|}
\hline Sample name & Gene & Position (ch: bp) & Nucleotide change & AA change & Variant rate $(\%)$ & SNV type \\
\hline 2008 & PIK3CA & 3: $178,936,091$ & G1633A & E545K & 47.9 & Non-synonymous \\
\hline A2780 & $A T M$ & $11: 108,123,551$ & $\mathrm{C} 1810 \mathrm{~T}$ & P604S & 25.7 & Non-synonymous \\
\hline Hac2 & $P I K 3 C A$ & 3: $178,952,085$ & A3140G & H1047R & 70.8 & Non-synonymous \\
\hline JHOC7 & KIT & 4: 55,593,461 & G1606C & V540L & 58.5 & Non-synonymous \\
\hline JHOC7 & $P I K 3 C A$ & 3: $178,936,082$ & G1624A & E542K & 35.8 & Non-synonymous \\
\hline JHOC8 & $F B X W 7$ & 4: $153,247,366$ & G1196A & R399Q & 75.3 & Non-synonymous \\
\hline JHOC8 & KIT & 4: 55,593,464 & A1621C & M541L & 99.8 & Non-synonymous \\
\hline JHOC8 & TP53 & $17: 7,578,406$ & G524A & $\mathrm{R} 175 \mathrm{H}$ & 99.6 & Non-synonymous \\
\hline JHOC9 & PIK3CA & $3: 178,936,082$ & G1624A & E542K & 96.1 & Non-synonymous \\
\hline MCAS & $K R A S$ & $12: 25,398,284$ & G35A & G12D & 80.7 & Non-synonymous \\
\hline MCAS & PIK3CA & 3: $178,952,085$ & A3140G & H1047R & 48.2 & Non-synonymous \\
\hline MCAS & SMAD4 & 18: 48,604,690 & $\mathrm{T} 1512 \mathrm{~A}$ & S504R & 95.1 & Non-synonymous \\
\hline OV-1063 & $R B 1$ & 13: 49,037,903 & A2143T & $\mathrm{K} 715 \mathrm{X}$ & 99.2 & Stop-gain \\
\hline OV-1063 & TP53 & $17: 7,578,181$ & $\mathrm{C} 272 \mathrm{~T}$ & P91L & 22.0 & Non-synonymous \\
\hline OV-1063 & TP53 & $17: 7,577,118$ & G820T & V274F & 59.0 & Non-synonymous \\
\hline RMG-1 & $C D K N 2 A$ & $9: 21,971,184$ & $\mathrm{~A} 217 \mathrm{C}$ & S73R & 100.0 & Non-synonymous \\
\hline SKOV-3 & $F B X W 7$ & 4: $153,247,288$ & G1274T & $\mathrm{R} 425 \mathrm{~L}$ & 44.8 & Non-synonymous \\
\hline SKOV-3 & PIK3CA & $3: 178,952,085$ & A3140G & H1047R & 46.0 & Non-synonymous \\
\hline SW626 & $K I T$ & $4: 55,593,464$ & A1621C & M541L & 48.3 & Non-synonymous \\
\hline SW626 & $K R A S$ & $12: 25,398,284$ & G35T & G12V & 51.0 & Non-synonymous \\
\hline SW626 & SMAD4 & 18: 48,591,888 & G1051C & D351H & 99.6 & Non-synonymous \\
\hline TYK-nu & KIT & 4: 55,593,464 & A1621C & M541L & 99.6 & Stop-gain \\
\hline TYK-nu & $N R A S$ & $1: 115,258,747$ & G35A & G12D & 33.7 & Non-synonymous \\
\hline TYK-nu & $N R A S$ & $1: 115,256,530$ & C181A & Q61K & 63.5 & Non-synonymous \\
\hline TYK-nu & TP53 & $17: 7,578,406$ & G524A & $\mathrm{R} 175 \mathrm{H}$ & 99.3 & Non-synonymous \\
\hline
\end{tabular}

itor, significantly suppressed the growth of a mouse xenograft of a human ovarian clear cell adenocarcinoma (35). In addition, molecular targeted therapies for tumors with CTNNB1 mutations and $C D K N 2 A$ inactivation have been indicated $(22,28)$, while tumors with $R B 1$ mutations are treatable by TORC inhibition based on synthetic lethality (28).

Importantly, the ability to prescribe a personalized therapy based on genetic alterations, guided by the single sequencing test described here, would be useful in clinical settings. Ovarian cancers in Japan include more non-serous cases than in other countries due to a higher fraction of clear cell cancers. Our study indicates that frequencies of the actionable alterations do not differ significantly by clinicopathological factors, therefore, analysis of all non-serous ovarian cancers at progressive stages will be an effective way to perform precision medicine of ovarian cancers based on actionable gene aberrations. In the strategy above, patients with serous ovarian cancers will not benefit from the therapy. However, recent studies have also suggested therapeutic approaches targeting p53 mutant proteins (36). Such approaches will benefit ovarian cancer patients with serous type ovarian cancer due to frequent TP53 mutations.

The present study has limitations. First, the utility of the above inhibitors has not been biologically proved. Gene aberration profiles for the same 46 genes were also obtained for 14 commonly used ovarian cancer cell lines (Table IV and Fig. 6). The results are consistent with those deposited in the COSMIC database (http:/cancer.sanger.ac.uk/cancergenome/projects/ cosmic/). PIK3CA and KRAS mutations are present in a subset of ovarian cancer cell lines, and consistent in vitro therapeutic responses by PI3K and MAPK inhibitors have been reported in a few cell lines (35-37). However, cell lines with other infrequent alterations were not detected in these cell lines. Thus, more sets of cultured ovarian cancer cells are needed to investigate the therapeutic significance of such gene alterations. Second, tumor suppressor and chromatin remodeling genes that lack mutation hotspots but are actionable for synthetic lethality therapy were not examined in the present study: BRCA1, BRCA2 and $A R I D 1 A$ are examples $(5,6,9)$. Tumors with $B R C A 1$ and $B R C A 2$ inactivation are susceptible to PARP1 inhibitors, while therapeutic strategies against tumors with ARIDIA inactivation are also proposed $(38,39)$. A more comprehensiveprofiling study including these genes are ongoing in our laboratory.

\section{Acknowledgements}

This study was supported by Grants-in-Aid from the Ministry of Health, Labor, and Welfare for Research for the 3rd Term Comprehensive 10-Year Strategy for Cancer 
Control and Promotion of Cancer Control Programs; and Extramural Collaborative Research Grant of Cancer Research Institute, Kanazawa University. M.T. and R.I. are awardees of the Research Resident Fellowship from the Foundation for Promotion of Cancer Research for the 3rd Term Comprehensive 10-Year Strategy for Cancer Control, Japan.

\section{References}

1. American Cancer Society: Cancer Facts \& Figures 2013. American Cancer Society Inc., http://www.cancer.org, Atlanta, 2013.

2. Haruta S, Furukawa N, Yoshizawa Y, Tsunemi T, Nagai A, Kawaguchi R, Tanase Y, Yoshida S and Kobayashi H: Molecular genetics and epidemiology of epithelial ovarian cancer (Review). Oncol Rep 26: 1347-1356, 2011.

3. Heintz AP, Odicino F, Maisonneuve P, Quinn MA, Benedet JL, Creasman WT, Ngan HY, Pecorelli S and Beller U: Carcinoma of the ovary. FIGO 26th Annual Report on the Results of Treatment in Gynecological Cancer. Int J Gynaecol Obstet Off Organ Int Fed Gynaecol Obstet 95: S161-S192, 2006.

4. Vaughan S, Coward JI, Bast RC Jr, Berchuck A, Berek JS, Brenton JD, Coukos G,Crum CC,Drapkin R,Etemadmoghadam D, et al: Rethinking ovarian cancer: recommendations for improving outcomes. Nat Rev Cancer 11: 719-725, 2011.

5. Jones S, Wang TL, Shih IeM, Mao TL, Nakayama K, Roden R, Glas R, Slamon D, Diaz LA Jr, Vogelstein B, et al: Frequent mutations of chromatin remodeling gene ARID1A in ovarian clear cell carcinoma. Science 330: 228-231, 2010.

6. Wiegand KC, Shah SP, Al-Agha OM,Zhao Y and Al E: ARID1A mutations in endometriosis-associated ovarian carcinomas. N Engl J Med 363: 1532-1543, 2011.

7. Bell D, Berchuck A, Birrer M, Chien J, Cramer D, Dao F, Dhir R, Di Saia P, Gabra H, Glenn P, et al: Integrated genomic analyses of ovarian carcinoma. Nature 474: 609-615, 2011.

8. Kanchi KL, Johnson KJ, Lu C, McLellan MD, Leiserson MD, Wendl MC, Zhang Q, Koboldt DC, Xie M, Kandoth C, et al: Integrated analysis of germline and somatic variants in ovarian cancer. Nat Commun 5: 3156, 2014.

9. Kalamanathan S, Bates V, Lord R and Green JA: The mutational profile of sporadic epithelial ovarian carcinoma. Anticancer Res 31: 2661-2668, 2011.

10. Kurman RJ and Shih I-M: Molecular pathogenesis and extraovarian origin of epithelial ovarian cancer - shifting the paradigm. Hum Pathol 42: 918-931, 2011.

11. Tuefferd M, Couturier J, Penault-Llorca F, Vincent-Salomon A, Broët P, Guastalla JP, Allouache D, Combe M, Weber B, PujadeLauraine E, et al: HER2 status in ovarian carcinomas: A multicenter GINECO study of 320 patients. PLoS One 2: e1138, 2007.

12. Ahmed AA, Etemadmoghadam D, Temple J, Lynch AG, Riad M, Sharma R, Stewart C, Fereday S, Caldas C, Defazio A, et al: Driver mutations in TP53 are ubiquitous in high grade serous carcinoma of the ovary. J Pathol 221: 49-56, 2010.

13. Kuo KT, Mao TL, Jones S, Veras E, Ayhan A, Wang TL, Glas R, Slamon D, Velculescu VE, Kuman RJ and Shih IeM: Frequent activating mutations of PIK3CA in ovarian clear cell carcinoma. Am J Pathol 174: 1597-1601, 2009.

14. Yamamoto S, Tsuda H, Takano M, Iwaya K, Tamai S and Matsubara O: PIK3CA mutation is an early event in the development of endometriosis-associated ovarian clear cell adenocarcinoma. J Pathol 225: 189-194, 2011

15. Singer G, Oldt R, Cohen Y, Wang BG, Sidransky D, Kurman RJ and Shih I-M: Mutations in BRAF and KRAS characterize the development of low-grade ovarian serous carcinoma. J Natl Cancer Inst 95: 484-486, 2003.

16. Gemignani ML, Schlaerth AC, Bogomolniy F, Barakat RR, Lin O, Soslow R, Venkatraman E and Boyd J: Role of KRAS and BRAF gene mutations in mucinous ovarian carcinoma. Gynecol Oncol 90: 378-381, 2003.

17. Mayr D, Hirschmann A, Löhrs U and Diebold J: KRAS and BRAF mutations in ovarian tumors: a comprehensive study of invasive carcinomas, borderline tumors and extraovarian implants. Gynecol Oncol 103: 883-887, 2006.

18. Chen JS, Lan K and Hung MC: Strategies to target HER2/neu overexpression for cancer therapy. Drug Resist Updat 6: 129-136, 2003.

19. Ross JS: Disease-free survival according to degree of HER2 amplification for patients treated with adjuvant chemotherapy with or without 1 year of trastuzumab: the HERA trial. Breast Dis 21: $378-380,2010$.
20. Bang YJ, van Cutsem E, Feyereislova A, Chung HC, Shen L, Sawaki A, Lordick F, Ohtsu A,Omuro Y, Satoh T, et al: Trastuzumab in combination with chemotherapy versus chemotherapy alone for treatment of HER2-positive advanced gastric or gastro-oesophageal junction cancer (ToGA): a phase 3, open-label, randomised controlled trial. Lancet 376: 687-697, 2010.

21. Carpten JD, Faber AL, Horn C, Donoho GP, Briggs SL, Robbins CM, Hostetter G, Boguslawski S, Moses TY, Savage S, et al: A transforming mutation in the pleckstrin homology domain of AKT1 in cancer. Nature 448: 439-444, 2007.

22. Anastas JN and Moon RT: WNT signalling pathways as therapeutic targets in cancer. Nat Rev Cancer 13: 11-26, 2013.

23. Ascierto PA, Schadendorf D, Berking C, Agarwala SS, van Herpen CM, Queirolo P, Blank CU, Hauschild A, Beck JT, St-Pierre A, et al: MEK162 for patients with advanced melanoma harbouring NRAS or Val600 BRAF mutations: a non-randomised, open-label phase 2 study. Lancet Oncol 14: 249-256, 2013.

24. Janku F, Wheler JJ, Naing A, Falchook GS, Hong DS, Stepanek VM, Fu S, Piha-Paul SA, Lee JJ, Luthra R, et al: PIK3CA mutation H1047R is associated with response to PI3K/AKT/mTOR signaling pathway inhibitors in early phase clinical trials. Cancer Res 73: 276-284, 2013.

25. Jänne PA, Shaw AT, Pereira JR, Jeannin G, Vansteenkiste J, Barrios C, Franke FA, Grinsted L, Zazulina V, Smith P, et al: Selumetinib plus docetaxel for KRAS-mutant advanced non-smallcell lung cancer: a randomised, multicentre, placebo-controlled, phase 2 study. Lancet Oncol 14: 38-47, 2013.

26. Sheppard KE and McArthur GA: The cell-cycle regulator CDK4: an emerging therapeutic target in melanoma. Clin Cancer Res 19: 5320-5328, 2013 .

27. Hutson TE, Escudier B, Esteban E, Bjarnason GA, Lim HY, Pittman KB, Senico P, Niethammer A, Lu DR, Hariharan S, et al: Randomized phase III trial of temsirolimus versus sorafenib as second-line therapy after sunitinib in patients with metastatic renal cell carcinoma. J Clin Oncol 32: 760-767, 2014.

28. Gordon GM, Zhang T, Zhao J and Du W: Deregulated G1/S control and energy stress contribute to the synthetic-lethal interactions between inactivation of RB and TSC1 or TSC2. J Cell Sci 126: 2004-2013, 2013.

29. Yamamoto S, Tsuda H, Takano M, Tamai S and Matsubara O: PIK3CA mutations and loss of ARID1A protein expression are early events in the development of cystic ovarian clear cell adenocarcinoma. Virchows Arch 460: 77-87, 2012.

30. Janku F, Wheler JJ, Westin SN, Moulder SL, Naing A, Tsimberidou AM, Fu S, Falchook GS, Hong DS, Garrido-Laguna I, et al: $\mathrm{PI} 3 \mathrm{~K} / \mathrm{AKT} / \mathrm{mTOR}$ inhibitors in patients with breast and gynecologic malignancies harboring PIK3CA mutations. J Clin Oncol 30: 777-782, 2012.

31. Yan M, Parker BA, Schwab R and Kurzrock R: HER2 aberrations in cancer: implications for therapy. Cancer Treat Rev 40: 770-780, 2014.

32. McAlpine JN, Wiegand KC, Vang R, Ronnett BM, Adamiak A, Köbel M, Kalloger SE, Swenerton KD, Huntsman DG, Gilks CB, et al: HER2 overexpression and amplification is present in a subset of ovarian mucinous carcinomas and can be targeted with trastuzumab therapy. BMC Cancer 9: 433, 2009.

33. Miller CR, Oliver KE and Farley JH: MEK1/2 inhibitors in the treatment of gynecologic malignancies. Gynecol Oncol 133: 128-137, 2014.

34. Koshiyama M, Matsumura N, Baba T, Yamaguchi K, Yoshioka Y and Konishi I: Two cases of recurrent ovarian clear cell carcinoma treated with sorafenib. Cancer Biol Ther 15: 22-25, 2014.

35. Bartholomeusz C, Oishi T, Saso H, Akar U, Liu P, Kondo K, Kazansky A, Krishnamurthy S, Lee J, Esteva FJ, et al: MEK1/2 inhibitor selumetinib (AZD6244) inhibits growth of ovarian clear cell carcinoma in a PEA-15-dependent manner in a mouse xenograft model. Mol Cancer Ther 11: 360-369, 2012.

36. Muller PA and Vousden KH: Mutant p53 in cancer: new functions and therapeutic opportunities. Cancer Cell 25: 304-317, 2014.

37. Honig A, Hahne JC, Meyer S, Kranke P, Häusler S, Diessner J, Dietl J and Engel JB: PI3K inhibitor D-116883 is effective in in vitro models of ovarian cancer. Anticancer Res 32: 2035-2041, 2012.

38. Chan DA and Giaccia AJ: Harnessing synthetic lethal interactions in anticancer drug discovery. Nat Rev Drug Discov 10: 351-364, 2011.

39. Helming KC, Wang X, Wilson BG, Vazquez F, Haswell JR, Manchester HE, Kim Y, Kryukov GV, Ghandi M, Aguirre AJ, et al: ARID1B is a specific vulnerability in ARID1A-mutant cancers. Nat Med 20: 251-254, 2014. 